Can positive and self-transcendent emotions promote pro-environmental behavior?

\author{
John M. Zelenski ${ }^{1}$ \& Jessica E. Desrochers ${ }^{1}$ \\ ${ }^{1}$ Department of Psychology, Carleton University, Ottawa, Canada
}

Correspondence concerning this article should be addressed to John M. Zelenski, Department of Psychology, Carleton University, 1125 Colonel By Dr, Ottawa, ON K1S 5B6, Canada. Email: john.zelenski@carleton.ca

A copyedited version of this paper appears in: Current Opinion in Psychology, 42, 31-35. https://doi.org/10.1016/j.copsyc.2021.02.009

Author's Notes

John M. Zelenski https://orcid.org/0000-0002-3668-5764

Jessica E Desrochers https://orcid.org/0000-0003-2754-3681 


\begin{abstract}
Many scholars have suggested that people could improve their well-being by developing closer connections with nature, and that this would also promote the sustainable behaviors needed to address climate change. Research generally corroborates this idea, but few studies have examined the more specific hypothesis that positive emotions (caused by nature or otherwise) can directly influence pro-environmental behaviors. In particular, self-transcendent emotions such as awe, compassion, and gratitude can be prompted by nature, and they seem to foster prosocial behaviors. Most pro-environmental behaviors are also pro-social; they require cooperation and they benefit others. Some recent studies suggest that self-transcendent emotions can cause pro-environmental behavior, though results are mixed overall. We identify strategies for future research to resolve these inconclusive suggestions.
\end{abstract}

Keywords: Self-transcendent emotions, pro-environmental behavior, connection to nature, happiness 


\section{Can positive and self-transcendent emotions promote pro-environmental behavior?}

Solving environmental problems, such as global climate change, is both urgent and complex. Undoubtedly, a broad set of changes will be needed, including those at structural and policy levels. Still, there is value in considering individual-level psychological processes. Individuals' behavior accumulates to (poor) environmental health, policy is responsive to constituents' wishes, and sustainable behaviors can spread through groups via changing norms. Even at the level of individual psychology, myriad processes_-subjectively pleasant, unpleasant, and neutral—can tilt us towards or away from sustainable choices. Here we explore the notion that pleasant emotions, and particularly a smaller subset of self-transcendent emotions (e.g., awe, gratitude, compassion), provide pleasant paths towards climate solutions. For example, a person might be spurred to environmental action after being moved by Jane Goodall's selfless efforts to protect chimpanzees, or perhaps after being struck by wonder after seeing these amazing creatures in a video. What is the evidence that such feelings can indeed prompt proenvironmental behaviors? Although this special issue focuses on climate change, we consider sustainable behaviors broadly under the contestable assumptions that many ultimately redound to climate change mitigation, and that the others are often psychologically similar to those that do.

\section{Pleasant Paths to Sustainable Behavior}

Human well-being depends on exploiting natural resources. Changing our exploitation patterns could interfere with happiness, yet climate change clearly demonstrates how the status quo also threatens it. Many scholars suggest that a modern disconnection from nature exacerbates cycles of self-defeating exploitation, whereas both happiness and sustainable behavior could result from closer human connections with nature [1]. These connections include 
both physical experience in nature and its subjective appreciation. Empirically, healthy natural spaces are particularly likely to boost moods $[2,3,4,5]$, and people who report strong personal connections with nature also tend to report higher well-being across a wide range of indicators spanning both hedonic and eudaimonic traditions $[6,7,8]$. Subjective nature relatedness strongly predicts pro-environmental attitudes and behaviors [9, 10]. These findings are consistent with the popular notion that people would treat the environment better, and reap wellbeing benefits, if they cultivated closer connections with nature. Nonetheless, experimental interventions demonstrating clear causal paths from nature connection to sustainability are limited [9].

Large surveys have also observed a positive link between pro-environmental behaviors per se and subjective well-being, though the correlation is smaller than the link between nature relatedness and well-being. Kasser [11] reviewed this work and entertained three plausible reasons for the correlation between sustainable behaviors and happiness, all of which are consistent with the limited data currently available. First, personality variables (such as voluntary simplicity, intrinsic motives, or nature relatedness) may account for the association via shared correlations and causal processes. Second, sustainable behaviors might cause happiness. That is, even though they are sometimes framed as costly or undesirable, sustainable behaviors are also pro-social behaviors - they help the planet and the people who live here. Other pro-social behaviors can boost happiness [12, 13, 14] and can occur without taxing self-regulation [15], though it is interesting to note that more effortful pro-environmental behaviors may have a stronger link with happiness [16]. Third, the reverse causal direction could (co-)exist, where happiness causes sustainable behaviors. Kasser [11] supports this explanation by appealing to a broad review of studies where induced pleasant moods seemed to cause pro-social behaviors 
[17]. This notion can also be seen as a broader version of the idea that the pleasant emotions generated by nature can produce sustainable behavior (emotion as mediator), and it suggests that positive emotions could drive pro-environmental behavior even when caused by things other than nature [18].

Despite abundant scholarship that is broadly consistent with the notion that happiness might increase sustainable behaviors, there are few direct, experimental tests of this idea. A recent exception induced positive affect (or neutral control) using video clips, and then gave participants the choice to exit the study sooner with an environmental cost (using electricity), or proceed slowly but with a better environmental outcome (less electricity used) [19]. Contrary to hypotheses, the affect induction did not have a significant effect on the environmental choice. Despite this null result, the authors took a cautious conclusion, wisely noting the wide variety of other pro-environmental behaviors, positive affects, and induction methods. For example, electricity use may be different than consumer choices, or awe may operate differently than joy. This particular set of variables did not produce a difference, but other sets might.

Similarly, the broad notion that happiness causes pro-social behavior lacks nuance, and the empirical record is not without ambiguity. Support for the clear causal effect in experiments seems to come primarily from studies conducted in the 1970s and 80s, with none later than 1994 in the Lyubomirsky et al. [17] or Aknin et al. [12] reviews. Older studies are suggestive, but confidence would increase with more recent replications and methods that heed the lessons of 'psychology's renaissance' [20]. Additionally, a recent meta-analysis found a near-zero association between trait positive affect and pro-social choices in economic games (e.g., prisoner's dilemma, dictator game, commons dilemmas) [21]. To be clear, we still conclude that the preponderance of the literature generally supports a link between happiness and pro-sociality. 
However, it seems likely that the family of narrower conclusions includes contexts or emotions that are more and less in line with this overarching idea.

\section{2 (Pleasant) Self-Transcendent Emotions}

Recent emotion research distinguishes a category of self-transcendent emotions that share the common features of shifting attention outside the self and fostering pro-social motivations and behaviors. Stellar et al. [22] structure their review around three of these self-transcendent emotions: compassion, gratitude, and awe. Compassion is typically elicited by seeing another person (or nonhuman animal, or perhaps even the environment generally) in need, and it motivates efforts to help. Gratitude occurs when receiving benefits due to another's intentional acts, and it fosters a desire to 'pay it forward' or reciprocate. Awe follows from the appraisal of vastness, novelty, and a lack of full understanding; the self then seems small in comparison, which can drive attachment to leaders and groups, along with the pro-social behaviors that characterize cooperative group members. Notably, awe can also be experienced in less pleasant ways, bordering on fear [23], and nature is prototypical of both pleasant (natural wonders) and unpleasant (natural disasters) awe elicitors. Our focus here is on pleasant awe experiences, consistent with the vast majority of empirical work. Future research and debate will adjudicate which emotions 'exist' as discrete entities, and other self-transcendent states may be added to the list or seen as blends in these emotion families, e.g., moral elevation, inspiration, pity, admiration, or kama muta ('being moved') [24, 25, 26, 27]. In sum, these self-transcendent emotions drive closer connections among people by prompting pro-social behaviors; this is seen as their ultimate evolutionary function. They may promote metaphorical connections with nature and pro-environmental behaviors too.

\section{Self-Transcendent Emotions Link to Environmentalism}


There are many conceptual links among nature, self-transcendent emotions, pro-social behavior and pro-environmental behavior. Exposure to nature can spark self-transcendent emotions [28], which are associated with pro-social behaviors; pro-environmental behaviors are often pro-social behaviors and require broad cooperation to be effective (e.g., limiting emissions). Direct tests of self-transcendent emotions on pro-environmental behavior are rare but suggestive. Awe, in particular, may have the strongest empirical links. For example, manipulated awe increased intentions to do a variety of personal conservation behavior (e.g., recycling or taking shorter showers) [29], the likelihood of individuals donating to an environmental nongovernment organization (e.g., World Wide Fund for Nature) in a dictator game [30], more proenvironmental purchasing intentions [31], and willingness for self-sacrifice to protect the environment [32]. Moreover, feelings of the self-transcendent emotion of awe towards nature was related to increased intentions for environmental behaviors (such as buying environmentally friendly goods and environmental policy support) [33]. However, moral elevation, an emotion similar to awe, shows inconsistent results with sustainability. Moreton et al. [34] examined how video-induced moral elevation increased individuals' connection to nature and environmental behaviors (such as intention to buy environmentally friendly products and other indicators from Tam et al [35]) in two studies. In Study 1, the induction of moral elevation did not cause proenvironmental behaviors, directly or indirectly through connection to nature [34]. In Study 2, there was no direct effect of the elevation induction on pro-environmental behavior, but the authors found an indirect (mediated) relationship through connection to nature [34].

Dispositional and induced compassion have been associated with greater intentions to perform environmental behaviors (such as recycling, water and energy conservation, environmentally friendly purchasing, and pro-environmental transportation) [36], support for government actions to mitigate climate change [37], and more sustainable decision making in entrepreneurs [38]. 
Additionally, those who had more compassion for others were more willing to change their lifestyles for climate change mitigation [39]. Compassion has also been used in framing environmental messages to influence individuals towards behaviors that help mitigate climate change effects; however, the results are mixed. When examining participants' willingness to volunteer their time for citizen science projects focused on wildlife, Greving and Kimmerle [40] found that induced compassion from images of distressed foxes mattered, but that induced compassion for distressed raccoons did not. Moreover, Markowitz et al. [41] found that compassion fade for animals, defined as a decrease in compassion as the number of suffering animals increased, differed in environmentalist versus non-environmentalist samples. Compassion decreased for animals dealing with climate change as the number of animals in the description was increased for the non-environmentalist group, whereas there was no effect of compassion fade in the environmentalist group [41]. The compassion fade reduced the likelihood of participants volunteering their time or donating their money for the affected animals [41].

The least amount of research has been done on gratitude and sustainability. Expressed gratitude towards nature was associated with increased care for nature and environmental behavior intentions in Japanese students [42]. Gratitude induced via a recollection task (but not general positive affect) caused participants to extract fewer excess resources (points) in a commons dilemma task, which although not framed as environmental per se, mirrors natural resource dilemmas (e.g., fishing, carbon emissions, etc.) [43]. A recent dissertation by Hamilton [44] found that spiritual gratitude rituals towards nature were associated with environmental values, but there was no association between gratitude rituals and pro-environmental behaviors.

\section{Implications and Future Research}

Across all three types of self-transcendent emotions, inconsistencies arise in links with environmentalism. Similar to pro-sociality, these inconsistencies could result from the 
differences in operationalizations of environmentalism and emotions in laboratory studies. The links seem encouraging, but not definitive, with almost no replication attempts reported. There are still relatively few robust, direct tests of causal processes, and so we do not take any firm conclusions about if or when self-transcendent emotions cause sustainable behavior. A plausible, if pessimistic, view can attribute the 'successes' reviewed here as mostly false positives amplified by publication bias [cf. 45]; the clear solution to this ambiguity is additional rigorous tests. This work will be aided by addressing some foundational issues with self-transcendent emotions. For example, when Nelson-Coffey and colleagues [46] induced awe through virtual reality, participants reported a mix of positive emotions, such as awe, gratitude, compassion, optimism, and love, indicating potential covariance between emotions; separating distinct selftranscendent emotions may be difficult, and testing for confounding states seems wise. It may also be wise to look for the most intuitive (strongest) connections before stretching the limits of what might be possible. For example, across 15 studies, Sparks et al. [47] found that individuals who viewed videos of pro-social behavior felt more moral elevation and then acted more prosocially themselves - there was a close link between manipulation and outcome here. Could environmentalism be more likely if the sources of self-transcendent emotions are seeing others' ecological behaviors or nature? In the lab, a desire to reduce demand effects might argue against using induction content that is close to dependent variables (i.e., nature or pro-environmental behavior as both), but misguided efforts towards methodological rigor can also create implausible contexts for effects. For example, should compassion induced via a struggling infant really cause people to take the bus a few minutes later? Our suggestion here can be seen in two ways: first that contextual moderators are important to the links between self-transcendent emotions and sustainable behavior, or alternatively, that the 'same' emotion functions differently 
depending on its source, mirroring difficult theoretical questions about how to parse emotion categories and definitions.

In addition, causal processes may well differ when looking at momentary effects, compared to the development of more enduring attitudes and identities. One experience sampling study showed that state compassion was related to increases in donations, but general trait compassion, measured at baseline, did not predict donations [48]. Moreover, Erickson et al. [49] found that inducing moral elevation through a series of viral videos produced immediate increases in feelings and pro-social goals, but they did not have sustained effects. Ultimately, meaningfully changing sustainable behaviors will require such enduring effects, and the processes that play out over months and years may involve different emotions. For example, even if the fascination of seeing birds build a nest does not produce an immediate sustainable shift (e.g., driving a moment later), it may still accumulate with other experiences in fostering an enduring sense of connection with nature, which then ultimately motivates a sustainable lifestyle. Future theory and research should remain open to the effects of self-transcendent emotions over longer timescales where experimental manipulations are often not feasible (though there are intriguing hints about the long-term effects of psilocybin in line with these ideas; see [50]).

In sum, our review of self-transcendent emotions as a path to mitigating climate change produced substantially more possibility than proof. If future research confirms these causal links, we suggest communication strategies based on emotional appeals and experiences. Pending that research, communicators might do it anyway based the authority of Jane Goodall who has persuaded policy makers and the masses, "If you want somebody to change their mind it's no good arguing; you've got to reach the heart." [51] 


\section{Reference}

[1] Tam, K. P. (2013). Concepts and measures related to connection to nature: Similarities and differences. Journal of Environmental Psychology, 34, 64-78. https://doi.org/10.1016/j.jenvp.2013.01.004

[2] Joye, Y., \& Bolderdijk, J.W. (2015). An exploratory study into the effects of extraordinary nature on emotions, mood, and prosociality. Frontiers in Psychology, 5(1577), 1-9. https://dx.doi.org/10.3389\%2Ffpsyg.2014.01577

[3] MacKerron, G., \& Mourato, S. (2013). Happiness is greater in natural environments. Global Environmental Change, 23(5), 992-1000. https://doi.org/10.1016/j.gloenvcha.2013.03.010

[4] Meidenbauer, K. L., Stenfors, C. U., Bratman, G. N., Gross, J. J., Schertz, K. E., Choe, K. W., \& Berman, M. G. (2020). The affective benefits of nature exposure: What's nature got to do with it?. Journal of Environmental Psychology, 72, 101498. https://doi.org/10.1016/j.jenvp.2020.101498

[5] McMahan, E. A., \& Estes, D. (2015). The effect of contact with natural environments on positive and negative affect: A meta-analysis. The Journal of Positive Psychology, 10(6), 507-519. https://doi.org/10.1080/17439760.2014.994224

[6] Capaldi, C. A., Dopko, R. L., \& Zelenski, J. M. (2014). The relationship between nature connectedness and happiness: A meta-analysis. Frontiers in Psychology, 5, 976. https://doi.org/10.3389/fpsyg.2014.00976

[7] Pritchard, A., Richardson, M., Sheffield, D., \& McEwan, K. (2020). The relationship between nature connectedness and eudaimonic well-being: A meta-analysis. Journal of Happiness Studies, 21, 1145-1167. https://doi.org/10.1007/s10902-019-00118-6 
[8] White, M. P., Alcock, I., Grellier, J., Wheeler, B. W., Hartig, T., Warber, S. L., Bone, A., Depledge, M. H., \& Fleming, L. E. (2019). Spending at least 120 minutes a week in nature is associated with good health and wellbeing. Scientific Report, 9, 7730.

\section{https://doi.org/10.1038/s41598-019-44097-3}

[9] Mackay, C. M. L. \& Schmitt, M. T. (2019) Do people who feel connected to nature do more to protect it? A meta-analysis. Journal of Environmental Psychology, 65, 101323. $\underline{\text { https://doi.org/10.1016/j.jenvp.2019.101323 }}$

* This meta-analysis confirms a strong link between trait nature connectedness and proenvironmental behavior, but it concludes that better studies are needed to confirm the weaker suggestions of causal effects in experiments.

[10] Whitburn, J., Linklater, W., \& Abrahamse, W. (2020). Meta-analysis of human connection to nature and proenvironmental behavior. Conservation Biology, 34(1), 180-193. https://doi.org/10.1111/cobi.13381

[11] Kasser, T. (2017). Living both well and sustainably: A review of the literature, with some reflections on future research, interventions and policy. Philosophical Transactions of the Royal Society A: Mathematical, Physical and Engineering Sciences, 375(2095), 20160369. https://doi.org/10.1098/rsta.2016.0369

* This review evidence for the positive correlation between happiness and pro-environmental behavior, and it explores possible reasons for this link.

[12] Aknin, L. B., Van de Vondervoort, J. W., \& Hamlin, J. K. (2018). Positive feelings reward and promote prosocial behavior. Current Opinion in Psychology, 20, 55-59. https://doi.org/10.1016/j.copsyc.2017.08.017 
[13] Curry, O. S., Rowland, L. A., Van Lissa, C. J., Zlotowitz, S., McAlaney, J. Whitehouse, H. (2018). Happy to help? A systematic review and meta-analysis of the effects of performing acts of kindness on the well-being of the actor. Journal of Experimental Social Psychology, 76, 320-329. https://doi.org/10.1016/j.jesp.2018.02.014

[14] Hui, B. P., Ng, J. C., Berzaghi, E., Cunningham-Amos, L. A., \& Kogan, A. (2020). Rewards of kindness? A meta-analysis of the link between prosociality and well-being. Psychological Bulletin, 146(12), 1084-1116. https://doi.org/10.1037/bul0000298

[15] Zaki, J., \& Mitchell, J. P. (2013). Intuitive prosociality. Current Directions in Psychological Science, 22(6), 466-470. https://doi.org/10.1177/0963721413492764

[16] Schmitt, M. T., Aknin, L. B., Axsen, J., \& Shwom, R. L. (2018). Unpacking the relationships between pro-environmental behavior, life satisfaction, and perceived ecological threat. Ecological Economics, 143, 130-140. https://doi.org/10.1016/j.ecolecon.2017.07.007

[17] Lyubomirsky, S., King, L., Diener, E. (2005) The benefits of frequent positive affect: Does happiness lead to success? Psychological Bulletin, 131(6), 803-855. https://doi.org/10.1037/0033-2909.131.6.803

[18] Spencer, S. J., Zanna, M. P., \& Fong, G. T. (2005). Establishing a causal chain: Why experiments are often more effective than mediational analyses in examining psychological processes. Journal of Personality and Social Psychology, 89(6), 845-851. https://doi.org/10.1037/0022-3514.89.6.845

[19] Lange, F., \& Dewitte, S. (2020). Positive affect and pro-environmental behavior: A preregistered experiment. Journal of Economic Psychology, 80, 102291. https://doi.org/10.1016/j.joep.2020.102291 
* Although results were null, this study exemplifies strong methods in testing the link between emotions and pro-environmental behaviors: pre-registration, multiple induction videos (good stimulus sampling), strong manipulation checks, and a behavioral outcome.

[20] Nelson, L. D., Simmons, J., \& Simonsohn, U. (2018). Psychology's renaissance. Annual Review of Psychology, 69, 511-534.

\section{https://doi.org/10.1146/annurev-psych-122216-011836}

[21] Thielmann, I., Spadaro, G., \& Balliet, D. (2020). Personality and prosocial behavior: A theoretical framework and meta-analysis. Psychological Bulletin, 146(1), 30-90. https://doi.org/10.1037/bul0000217

[22] Stellar, J. E., Gordon, A. M., Piff, P. K., Cordaro, D., Anderson, C. L., Bai, Y., Maruskin, L. A., \& Keltner, D. (2017). Self-transcendent emotions and their social functions: Compassion, gratitude, and awe bind us to others through prosociality. Emotion Review, 9(3), 200-207. https://doi.org/10.1177/1754073916684557

* This review outlines recent theory and research on the functions and correlates of selftranscendent emotions.

[23] Gordon, A. M., Stellar, J. E., Anderson, C. L., McNeil, G. D., Loew, D., \& Keltner, D. (2017). The dark side of the sublime: Distinguishing a threat-based variant of awe. Journal of Personality and Social Psychology, 113(2), 310-328. https://doi.org/10.1037/pspp0000120

[24] Pohling, R., \& Diessner, R. (2016). Moral elevation and moral beauty: A review of the empirical literature. Review of General Psychology, 20(4), 412-425. https://doi.org/10.1037/gpr0000089 
[25] Thomson, A. L., \& Siegel, J. T. (2017). Elevation: A review of scholarship on a moral and other-praising emotion. The Journal of Positive Psychology, 12(6), 628-638. https://doi.org/10.1080/17439760.2016.1269184

[26] Yaden, D. B., Haidt, J., Hood, R. W., Jr., Vago, D. R., \& Newberg, A. B. (2017). The varieties of self-transcendent experience. Review of General Psychology, 21(2), 143-160. https://doi.org/10.1037/gpr0000102

[27] Zickfield, J. H., Schubert, T. W., Seibt, B., \& Fiske, A. P. (2019). Moving through the literature: What is the emotion often denoted being moved? Emotion Review, 11(2), 123139. https://doi.org/10.1177/1754073918820126

[28] Neill, C., Gerard, J., \& Arbuthnott, K. D. (2019). Nature contact and mood benefits: contact duration and mood type. The Journal of Positive Psychology, 14(6), 756-767. https://doi.org/10.1080/17439760.2018.1557242

* This paper reports studies which show boosts in self-transcendent emotions following nature exposure inductions, and also explores other method features such as duration.

[29] Yang, Y., Hu, J., Jing, F., \& Nguyen, B. (2018). From awe to ecological behavior: The mediating role of connectedness to nature. Sustainability, 10, 2477. https://doi.org/10.3390/su10072477

[30] Ibanez, L., Moureau, N., \& Roussel, S. (2017). How do incidental emotions impact proenvironmental behavior? Evidence from the dictator game. Journal of Behavioral and Experimental Economics, 66, 150-155. https://doi.org/10.1016/j.socec.2016.04.003

[31] Wang, L., Zhang, G., Shi, P., Lu, X., \& Song, F. (2019). Influence of awe on green consumption: The mediating effect of psychological ownership. Frontiers in Psychology, 10, 2484. https://doi.org/10.3389/fpsyg.2019.02484 
[32] Zhao, H., Zhang, H., Xu, Y., Lu, J., \& He, W. (2018). Relation between awe and environmentalism: The role of social dominance orientation. Frontiers in Psychology, 9, 2367. https://doi.org/10.3389/fpsyg.2018.02367

[33] Bethelmy, L. C., \& Corraliza, J. A. (2019). Transcendence and sublime experience in nature: Awe and inspiring energy. Frontiers in Psychology, 10, 509. https://doi.org/10.3389/fpsyg.2019.00509

[34] Moreton, S. G., Arena, A., Hornsey, M. J., Crimston, C. R., \& Tiliopoulos, N. (2019). Elevating nature: Moral elevation increases feelings of connectedness to nature. Journal of Environmental Psychology, 65, 101332. https://doi.org/10.1016/j.jenvp.2019.101332

[35] Tam, K.-P., Lee, S.-L., \& Chao, M. M.. (2013). Saving Mr. Nature: Anthropomorphism enhances connectedness to and protectiveness toward nature. Journal of Experimental Social Psychology, 49(3), 514-521. https://doi.org/10.1016/j.jesp.2013.02.001

[36] Pfattheicher, S., Sassenrath, C., \& Schindler, S. (2016). Feelings for the suffering of others and the environment: Compassion fosters proenvironmental tendencies. Environment and Behavior, 48(7), 929-945. https://doi.org/10.1177/0013916515574549

[37] Lu, H., \& Schuldt, J. P. (2016). Compassion for climate change victims and support for mitigation policy. Journal of Environmental Psychology, 45, 192-200. https://doi.org/10.1016/j.jenvp.2016.01.007

[38] Engel, Y., Ramesh, A., \& Steiner, N. (2020). Powered by compassion: The effect of lovingkindness meditation on entrepreneurs' sustainable decision-making. Journal of Business Venturing, 35(6), 105986. https://doi.org/10.1016/j.jbusvent.2019.105986 
[39] [Dickinson, J. L., McLeod, P., Bloomfield, R., \& Allred, S. (2016). Which moral foundations predict willingness to make lifestyle changes to avert climate change in the USA? PLOS ONE, 11(10): e0163852. https://doi.org/10.1371/journal.pone.0163852

[40] Greving, H., \& Kimmerle, J. (2020). You poor little thing! The role of compassion for wildlife conservation. Human Dimensions of Wildlife, 1-17. https://doi.org/10.1080/10871209.2020.1800146

[41] Markowitz, E. M., Slovic, P., Västfjäll, D., \& Hodges, S. D. (2013). Compassion fade and the challenge of environmental conservation. Judgment and Decision Making, 8(4), 397406.

[42] Naito, T., Matsuda, T., Intasuwan, P., Chuawanlee, W., Thanachanan, S., Ounthitiwat, J., \& Fukushima, M. (2010). Gratitude for, and Regret Toward, Nature: Relationships to Proenvironmental Intent of University Students from Japan. Social Behavior and Personality: An International Journal, 38(7), 993-1008. https://doi.org/10.2224/sbp.2010.38.7.993

[43] Kates, S., \& DeSteno, D. (In Press). Gratitude Reduces Consumption of Depleting Resources. Emotion. https://doi.org/10.31234/osf.io/k95rj

[44] Hamilton, M. P. K. (2019). Rituals expressing gratitude to nature and proenvironmentalism: A multiple case study of long-term participation. [Doctoral dissertation, Royal Roads University]. ProQuest Dissertations Publishing. https://search.proquest.com/openview/8fea6ddd6444ed86efd36f9da4b7d018/1?pqorigsite $=$ gscholar $\& \mathrm{cbl}=18750 \&$ diss $=\mathrm{y}$

[45] Vohs, K. D., Schmeichel, B. J., Lohmann, S., Gronau, Q., Finley, A. J... Wagenmakers, E.- 
J., \& Albarracín, D. (in press). A multi-site preregistered paradigmatic test of the ego depletion effect. Psychological Science. [retrieved from https://psyarxiv.com/e497p/]

[46] Nelson-Coffey, S. K., Ruberton, P. M., Chancellor, J., Cornick, J. E., Blascovich, J., Lyubomirsky, S. (2019) The proximal experience of awe. PLoS ONE 14(5): e0216780. https://doi.org/10.1371/journal.pone.0216780

[47] Sparks, A. M., Fessler, D. M., \& Holbrook, C. (2019). Elevation, an emotion for prosocial contagion, is experienced more strongly by those with greater expectations of the cooperativeness of others. PloS one, 14(12), e0226071. https://doi.org/10.1371/journal.pone.0226071

[48] Runyan, J. D., Fry, B. N., Steenbergh, T. A., Arbuckle, N. L., Dunbar, K., \& Devers, E. E. (2019). Using experience sampling to examine links between compassion, eudaimonia, and pro-social behavior. Journal of Personality, 87(3), 690-701. https://doi.org/10.1111/jopy.12426

[49] Erickson, T. M., McGuire, A. P., Scarsella, G. M., Crouch, T. A., Lewis, J. A., Eisenlohr, A. P., \& Muresan, T. J. (2017). Viral videos and virtue: Moral elevation inductions shift affect and interpersonal goals in daily life. The Journal of Positive Psychology, 13(6), 643-654. https://doi.org/10.1080/17439760.2017.1365163

[50] Moreton, S. (2018). Can self-transcendent positive emotions facilitate bonds with nature? https://doi.org/10.31234/osf.io/deq8z

[51] Leiter, E. \& Woodard, K. (Directors). (2021). Jane Goodall: The Hope. [Documentary Film]. National Geographic. 